Jurnal Ekonomi Syariah Darussalam

Vol I No I Agustus 2020, ISSN: 2745-8407

\title{
STRATEGI PEMASARAN PRODUK-PRODUK GADAI SYARIAH DALAM MENINGKATKAN JUMLAH NASABAH DITINJAU DARI PERSPEKTIF ISLAM
}

\author{
Nelly Rahmatillah ${ }^{1}$, Uswatun Hasanah ${ }^{2}$ \\ IAI Qomaruddin Gresik', Institut Agama Islam Darussalam Blokagung \\ Banyuwangi ${ }^{2}$ \\ Email: jznely01@gmail.com ${ }^{1}$, Tsabitqalbi97@gmail.com²
}

\begin{abstract}
Pegadaian is a non-bank financial company that is often referred to as a company "Overcoming Problems without Problems" whose function is to help public finance urgent nature. This study aims to determine the marketing strategy of sharia pawn products at PT. Pegadaian (Persero) Syariah Simpang Lima Banyuwangi in marketing products sharia pawn Simpang Lima Banyuwangi in terms of perspective from Islam. This research data uses primary data using data. PT. Pegadaian (Persero) Syariah Simpang Lima Banyuwangi is legitimate because it is in accordance with promotions that are permitted in Islam and is related to the characteristics of the Prophet when he carried out promotions (marketing) and marketing strategy undertaken by PT. Pegadaian (Persero) Syariah Simpang Lima Banyuwangi is able to influence the growth in the number of promotional systems used by PT. Banyuwangi Syariah Pegadaian can be seen from the results of the SWOT analysis consisting of IFAS matrices namely strengths and weaknesses and the EFAS Matrix that is, opportunities and threats so that they will show the results of the SWOT.
\end{abstract}

\section{Keywords: Marketing Strategy, Promotion System, Customers}

\begin{abstract}
Abstrak
Pegadaian adalah perusahaan keuangan bukan bank yang sering di sebut sebagai perusahaan "Mengatasi Masalah Tanpa Masalah" fungsinya untuk membantu keuangan masyarakat yang sifatnya mendesak. Penelitian ini bertujuan mengetahui strategi pemasaran produk gadai syariah yang di PT. Pegadaian (persero) Syariah Simpang Lima Banyuwangi dalam memasarkan produk Gadai Syariah Simpang Lima Banyuwangi di tinjau dari perspektif Islam. Data penelitian ini menggunakan data primer menggunakan data. PT. Pegadaian (persero) Syariah Simpang Lima Banyuwangi sah karena sudah sesuai dengan promosi yang di perbolehkan dalam Islam dan berhubungan dengan sifat-sifat Rasulullah SAW ketika melakukan promosi (pemasaran) dan strategi pemasaran yang dilakukan oleh PT. Pegadaian (persero) Syariah Simpang Lima Banyuwangi mampu mempengaruhi pertumbuhan jumlah sistem promosi yang digunakan oleh perusahaan dapat dilihat dari hasil analisis SWOT terdiri dari matrik IFAS yakni kekuatan dan kelemahan serta Matrik EFAS yakni peluang dan ancaman sehingga akan menunjukkan hasil dari analisis SWOT.
\end{abstract}

Kata Kunci: Strategi Pemasaran, Sistem Promosi, Nasabah 
Jurnal Ekonomi Syariah Darussalam

Vol I No I Agustus 2020, ISSN: 2745-8407

\section{A. PENDAHULUAN}

Pegadaian adalah perusahaan keuangan bukan bank yang sering di sebut sebagai perusahaan "Mengatasi Masalah Tanpa Masalah" fungsinya untuk membantu keuangan masyarakat menengah kebawah yang membutuhkan dana yang sifatnya mendesak seperti untuk biaya pendidikan anak sekolah, biaya kematian, dan biaya mendesak lainnya. Sistem pemasaran yang digunakan Pegadaian Syariah yaitu dengan cara sebar brosur, literasi, dan iklan. Sistem promosi ini dapat dilihat hasilnya dengan melihat banyak nya jumlah nasabah yang mengalami peningkatan dari tahun ketahun. Sesuai hadist yang telah disebutkan bahwa rahn (gadai) merupakan salah satu solusi yang mempunyai landasan/ panutan yang sesuai dengan syariat Islam dan dicontohkan Rasulullah dalam mengatasi kebutuhan dana. Islam juga mengajarkan perekonomian yang syariah yang membantu manusia untuk memilih jalan yang lebih baik. Rahn atau yang lebih dikenal dengan gadai sendiri pernah dipraktekkan oleh Rasulullah sebagaimana yang diterangkan dalam sebuah hadis yang bersumber dari "Aisyah Radhiyallahuanha" :

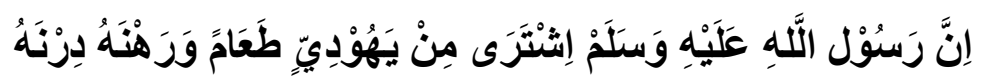

Artinya: "Sesungguhnya Rasulullah Shalallahu ,alaihi wa sallam membeli makanan dari orang Yahudi dan beliau menggadaikan baju besinyakepadanya" (Riwayat al-Bukhari dan Muslim).

Strategi pemasaran merupakan rencana di bidang pemasaran yang memberikan pedoman tentang kegiatan yang akan dilakukan dalam mencapai tujuan. Dengan melakukan sistem promosi melalui periklanan, literasi, sebar brosur, reveral, telle marketing, sosial media, program promosi, penjualan, program produk, dan pendistribusian. Kemampuan perencanaan yang baik dan matang adalah bagian dari anjuran Allah. Manajemen strategi dapat ditentukan oleh kombinasi faktor internal dan eksternal, kedua faktor tersebut harus dipertimbangkan dalam analisis SWOT. SWOT merupakan singkatan dari lingkungan Internal Strengths dan Weaknesses serta lingkungan eksternal Opportunities dan Threats yang dihadapi dunia bisnis. Analisis SWOT membandingkan antara faktor eksternal peluang (opportunities) dan ancaman (threats) dengan faktor internal kekuatan (strengths), dan kelemahan (weaknesses) (Rangkuti, 2018:20). Maka dari itu untuk menganalisis strategi pemasaran produk-produk syariah menggunakan analisis SWOT untuk mengetahui 
Jurnal Ekonomi Syariah Darussalam

Vol I No I Agustus 2020, ISSN: 2745-8407

faktor internal dan eksternalnya. Mengenai proses strategi pemasaran produkproduk Gadai Syariah dalam meningkatkan jumlah nasabah di tinjau dari perspektif Islam yang dilakukan Pegadaian Syariah untuk menentukan apakah strategi pelayanan Islami yang diterapkan oleh Pegadaian Syariah dapat meningkatkan minat masyarakat untuk menjadi loyal kepada pegadaian dan nasabah mendapat kepuasan terhadap strategi pemasaran yang Islami yang diberikan oleh Pegadaian Syariah dibanding dengan lembaga keuangan non bank syariah yang lainnya. Dari latar belakang tersebut maka peneliti dapat merumuskan masalah sebagai berikut: 1) Bagaiman strategi pemasaran produk-produk Gadai Syariah yang dilakukan oleh PT. Pegadaian (Persero) Syariah Simpang Lima Banyuwangi? 2) Bagaimana strategi pemasaran produk-produk Pegadaian Syariah Simpang Lima Banyuwangi di tinjau dari Pespektif Islam?

\section{B. LANDASAN TEORI}

\section{Pengertian Pemasaran Syariah}

Pemasaran ditinjau dari perspektif Islam dan Al-Qur'an Menurut prinsip syariah, kegiatan pemasaran harus dilandasi semangat beribadah kepada Tuhan Sang Maha Pencipta, berusaha semaksimal mungkin untuk kesejahteraan bersama, bukan untuk kepentingan-kepentingan golongan lainnya apalagi kepentingan sendiri. Rasulullah SAW telah mengajarkan pada umatnya untuk berdagang dengan menjunjung tinggi etika keislaman, dalam beraktivitas ekonomi umat Islam dilarang melakukan tindakan bathil (Firmansyah, 2019:19). Namun harus melakukan kegiatan ekonomi yang dilakukan saling ridho, sebagaimana firman Allah, dalam Al-Qur'an terjemah bi Rosm Usmani surat An-Nisa' Ayat 29 yang berbunyi:

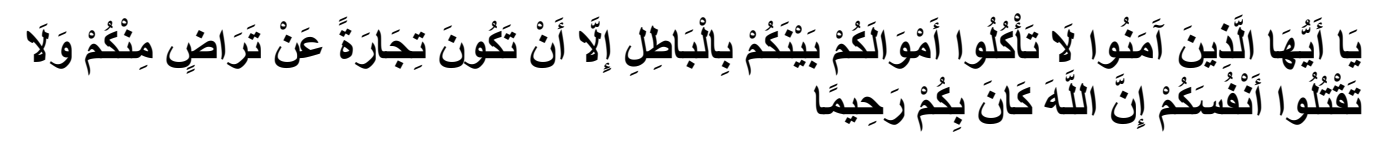

Artinya: "Wahai orang-orang yang beriman, janganlah kalian memakan hartaharta kalian di antara kalian dengan cara yang batil, kecuali dengan perdagangan yang kalian saling ridha. Dan janganlah kalian membunuh diri-diri kalian, sesungguhnya Allah itu Maha Kasih Sayang kepada kalian" (QS. An-Nisa ayat 29).

Pemasaran syariah merupakan salah satu kegiatan dalam perekonomian yang membantu dalam menciptakan nilai ekonomi. Nilai ekonomi itu sendiri 
Jurnal Ekonomi Syariah Darussalam

Vol I No I Agustus 2020, ISSN: 2745-8407

menentukan harga barang dan jasa, faktor penting dalam menciptakan nilai tersebut adalah produksi, pemasaran dan konsumsi. Pemasaran menjadi penghubung antara kegiatan produksi dan konsumsi. Dalam kitab HR. Bukhori telah di terangkan bahwa (Sudiono, 2004:5):

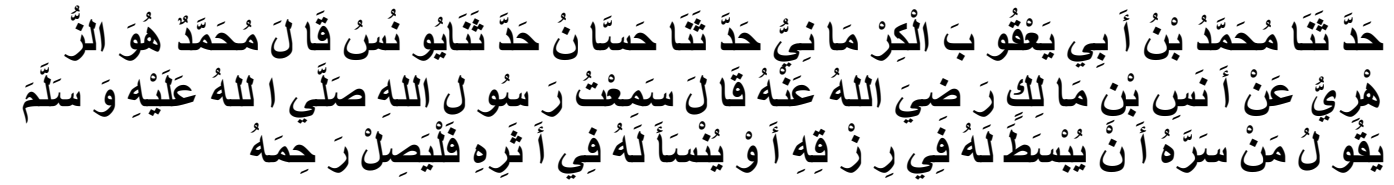

Artinya: "Telah menceritakan kepada kami Muhammad bin Ya'kub Al-Karim telah menceritakan kepada kami Hasan dari Yunus dari Muhammad Zuhri dari Anas bin Malik dia berkata, Rasulullah shallallahu 'alaihi wasallam telah bersabda: barang siapa yang ingin dilapangkan rezekinya atau di panjangkan umurnya, maka bersilaturahmilah" (Matan lain; Muslim 4638, Abi Daud 1443, Ahmad 12128).

Karakteristik pemasaran Islam dikemukakan bahwa ada 4 (empat) karakteristik pemasaran syariah (syariah marketing) yang dapat menjadi panduan bagi pemasaran yaitu (Kertajaya, 2016:28):

1. Teistis (Rabbaniyah), yaitu salah satu ciri khas syariah marketing yang tidak dimiliki dalam pemasaran konvensional yang di kenal selama ini adalah sifatnya yang religius (diniyyah).

2. Etis (Akhlaqiyyah), yaitu keistimewaan yang lain dari syariah marketer selain karena teitis (rabbaniyyah), juga karena sangat mengendapkan masalah akhlak (moral, etika) dalam seluruh aspek kehidupannya.

3. Realistis (Al-waqi'iyyah), yaitu syariah marketing bukanlah konsep yang eksklusif, fanatis, anti modernitas dan kaku.

4. Humanistis (Al-insaniyyah), yaitu keistimewaan syariah marketing yang lain adalah sifatnya yang humanistis universal.

\section{Bauran Pemasyaran Syariah (Marketing Mix Syariah)}

Jika berbicara marketing mix, tentu kita akan langsung teringat pada Jerome Mc Carhty, dialah tokoh yang di kenal sebagai "Bapak" marketing mix atau yang juga di kenal sebagai konsep product, price, place, dan promotion (4p). Berkat beliau konsep $4 p$ kemudian di kenal luas oleh masyarakat dan sering menjadi rujukan jika membahas tentang pemasaran. Pandangan Islam tentang empat unsur Marketing Mix Syariah yaitu (Sula, 2016:12): 
Jurnal Ekonomi Syariah Darussalam

Vol I No I Agustus 2020, ISSN: 2745-8407

\section{Produk (Product)}

Dalam ajaran Islam produk yang dijual belikan harus halal dan thayyib, perintah tentang produk yang halal dan thayyib berulang kali disebut dalam AlQur'an, antara lain surah An-Nahl ayat 114, sebagai berikut (Sula, 2016:21):

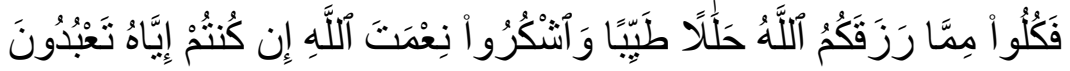

Artinya: "Maka makanlah yang halal lagi baik dari rezki yang telah diberikan Allah kepadamu; dan syukurilah nikmat Allah, jika kamu hanya kepadaNya saja menyembah" (Al-Qur'an terjemah Rosm Usmani, Qs. Al-Nahl Ayat 114).

\section{Harga (Price)}

Dalam setiap keputusan yang diambil seorang marketer Islami harus dilandasi dengan keadilan ekonomi dan kemaslahatan. Sikap keadilan ekonomi merupakan sikap untuk membuat setiap individu mendapatkan haknya sesuai kontribusi masing-masing kepada masyarakat serta setiap individu harus bebas dari eksploitasi individu lainnya, sehingga Islam mengharamkan segala bentuk hal yang merugikan bagi orang lainnya.

\section{Tempat (Place)}

Pengangkutan merupakan salah satu fungsi yang penting di dalam marketing, dan memberikan pengaruh yang sangat besar di dalam pembentukan harga.

\section{Promosi (Promotion)}

Marketing dimaknai sebagai dakwah, karena hal ini telah di perlihatkan dan pada dasarnya pedagang dalam menjual dan mempromosikan barangnya juga mempromosikan nilai-nilai Islam. Lebih lanjut lagi Rasulullah SAW mewajibkan agar tidak melakukan sumpah palsu yaitu usaha yang dilakukan untuk melariskan barang dagangannya dengan cara yang tercela (Sula, 2016:28).

\section{Promosi yang Diperbolehkan dalam Islam}

Promosi dalam syariat Islam sudah diterangkan bahwa mempromosikan suatu barang atau produk itu diperbolehkan. Syariat Islam juga mengajarkan cara promosi yang baik yaitu berpromosi dengan cara mengedepankan faktor kejujuran dan tidak diperbolehkan melakukan unsur penipuan (Kalimah, dkk, 2017:45).

\section{Pengertian Akad Rahn}

Rahn secara bahasa adalah Al-Habsu الحبس yang artinya tertahan ini sesuai dengan ayat: 
Jurnal Ekonomi Syariah Darussalam

Vol I No I Agustus 2020, ISSN: 2745-8407

$$
\text { كُلُْ نَفْسِ بِمَا كَسَبَتْْ رَهِينَةٌُ (المدسر: 38) }
$$

Artinya: "Tiap-tiap manusia mempunyai rasa tanggung jawab atas apa yang telah diperbuatnya”.

Tafsiran ayat tersebut menurut Syekh Wahbah Az-Zuhaily dalam kitabnya almu'tamad yaitu setiap orang itu tertahan masuk surga sebab perbuatan yang dilakukan di dunia, sampai Allah menghisab amalnya sampai tuntas. (Muhammad Az-Zuhaily, 1999:365). Dan didalam Kitab Qulyubi Wa 'Amirah karangan Syekh Syihabudin Al-Qulyubi beliau menguatkan ayat tersebut dengan hadist fiqih muamalah:

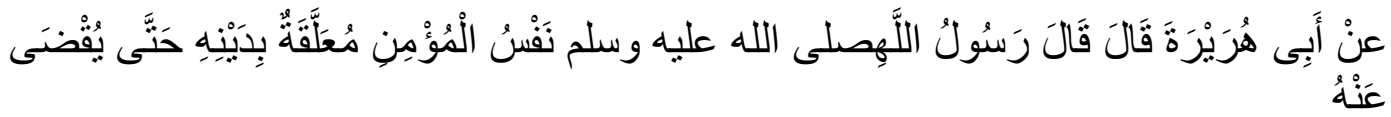

Artinya: "Abu Hurairah Radhiyallahu 'Anhu tealah mengatakan: "Rasulullah Shallallahu 'Alaihi Wasallam Bersabda: "Ruh manusia yang beriman tergantung pada hutangnya, sampai dia dilunasi hutangnya" HR. Tirmidzi.

\section{Rukun Akad Gadai}

Rahn (gadai) ada rukun dan syarat-syarat nya yang harus di penuhi agar rahn tersebut sah dan tidak melanggar hukum Islam, ada beberapa rukun rahn yaitu: 1) Orang yang menggadaikan (rahin), 2) Orang yang terima gadai (murtahin), 3) Benda yang digadaikan (marhun), 4) Barang yang akan ditanggung (marhun bih) dan 5) Shighat atau akad.

\section{Penelitian Terdahulu yang Relevan}

Yuliar Diyanti pada tahun 2018, penelitian dengan judul "Analisis SWOT sebagai Strategi Meningkatkan Daya Saing Usaha Tahu di Desa Hajoran Kecamatan Sungai Kanan Kabupaten Labuhan”. Bank Syariah memperhatikan kualitas produk (Service Quality/Servqual), yang terdiri atas 5 (lima) dimensi yaitu: AssuranceI, ReliabilityI, Tangible, Emphaty, dan Responsiveness, yang kemudian dikembangkan menjadi 6 dimensi yang dikenal dengan Model CARTER dengan tambahan dimensi compliance, maka akan tercapai kepuasan nasabah terhadap pelayanan di Bank Syariah yang tentunya akan meningkatkan loyalitas nasabah di Bank Syariah yang pada akhirnya akan meningkatkan kinerja keuangan Bank Syariah itu sendiri. Persamaan dalam penelitian ini adalah penelitian lapangan (field research), metode yang digunakan adalah kualitatif pengumpulan data dengan observasi, wawancara dan dokumentasi, dan menggunakan data analisis SWOT. 
Jurnal Ekonomi Syariah Darussalam

Vol I No I Agustus 2020, ISSN: 2745-8407

Sedangkan perbedaannya terletak pada terletak pada lokasi penelitian, objeknya, dan variabelnya (Yuliar Diyanti, 2018).

Meutia Resky Oisina pada tahun 2018 penelitian dengan judul "Analisis SWOT Strategi Pemasaran Produk Produk Pembiayaan pada Pegadaian Syariah”. Strategi pemasaran syariah dalam meningkatkan penjualan produk catering menetapkan berbagai prinsip syariah yaitu kegiatan promosi yang dilakukan dengan jujur dalam menginformasikan gambar dan suatu produknya tanpa menggunakan sumpah-sumpah, serta pelayanan konsumen yang menerapkan etika berbisnis dengan memperhatikan kejujuran, keramah-tamahan, dan menerapkan prinsip bisnis Islami dalam bentuk nilai-nilai shiddiq, fathanah, amanah, dan tabligh. Persamaan dengan penelitian ini adalah terletak pada jenis penelitian merupakan penelitian lapangan (field research), pengumpulan data dilakukan dengan wawancara, observasi dan analisis data yang digunakan adalah analisis SWOT dan dianalisis dengan cara diskriptif kualitatif untuk memperoleh kesimpulan. Sedangkan perbedaannya terletak pada lokasi penelitian (Meutia Resky Oisina, 2018).

\section{METODE PENELITIAN}

\section{Jenis Penelitian}

Adapun jenis penelitian kualitatif dan merupakan penelitian studi kasus yang dilakukan berada di PT. Pegadaian (Persero) Unit Pegadaian Syariah Simpang Lima di Kabupaten Banyuwangi yang membahas tentang strategi pelayanan Islami.

\section{Lokasi dan Waktu Penelitian}

Lokasi penelitian di lakukan di PT. Pegadaian (Persero) Unit Pegadaian Syariah Simpang Lima di Kabupaten Banyuwangi yang beralamatkan di Jln. MT Haryono No. 68 Karangrejo Kecamatan Banyuwangi Kabupaten Banyuwangi. Adapun waktu pelaksanaanya yaitu dimulai pada Bulan Maret sampai Agustus Tahun 2019.

\section{Data dan Sumber Data}

Data primer ini dengan cara diperoleh langsung dari hasil observasi dan wawancara dengan pimpinan, karyawan, nasabah PT. Pegadaian (Persero) Unit Pegadaian Syariah Simpang Lima di Kabupaten Banyuwangi dan sumber ahli ekonomi Islam yang berasal dari Pondok Pesantren Darussalam Blokagung 
Jurnal Ekonomi Syariah Darussalam

Vol I No I Agustus 2020, ISSN: 2745-8407

Banyuwangi. Dalam pengumpulan data sekunder ini dengan cara diperoleh dari bentuk dokumen-dokumen Pegadaian Syariah di Kabupaten Banyuwangi, seperti: 1) Sejarah Pegadaian Syariah Simpang Lima di Kabupaten Banyuwangi, 2) Visi dan misi perusahaan Pegadaian Syariah Simpang Lima di Kabupaten Banyuwangi, 3) Struktur organisasi Pegadaian Syariah Simpang Lima di Kabupaten Banyuwangi.

\section{Teknik Pengumpulan Data}

Pengumpulan data dalam penelitian ini dilakukan dengan cara observasi, wawancara/Interview, dan dokumentasi.

\section{Teknik Analisis Data}

Metode analisis data yang digunakan adalah analisis SWOT yang terdiri dari: Matrik IFAS adalah internal strategic Faktors Analysis Summary yaitu faktorfaktor strategis internal suatu perusahaan. Sedangkan matrik EFAS adalah eksternal strategic Faktors Analisis Summary yaitu faktor-faktor strategis eksternal suatu perusahaan. Keduanya dibandingkan yang dapat menghasilkan alternatif strategi (S-O, S-T, W-O, W-T).

Matriks SWOT adalah sebuah alat pencocokan yang penting untuk membantu manajer mengembangkan empat jenis strategi, strategi SO (kekuatan-peluang), strategi WO (kelemahan-peluang), strategi ST (kekuatan-ancaman), strategi WT (kelemahan-ancaman).

\section{HASIL DAN PEMBAHASAN}

\section{Lahirnya Pegadaian Syariah}

Pegadaian telah Terbitnya PP/10 tanggal 1 April 1990 dan dapat dikatakan banyak pihak berpendapat bahwa operasionalisasi pegadaian sebelum Fatwa MUI tanggal 16 Desember 2003, misi ini tidak berubah hingga menjadi PT. Pegadaian, menjadi tonggak awal kebangkitan pegadaian. Satu hal yang perlu dicermati bahwa PP. 10 menegaskan misi dan yang harus diemban oleh orangorang pegadaian untuk mencegah praktik riba tentang bunga bank, berkat Rahmat Allah SWT yang setelah itu meraka melakukan kajian panjang, dan pada akhirnya disusunlah suatu konsep yang pendirian Unit Layanan Gadai Syariah sebagai langkah yang awal dan dapat pembentukan divisi khusus yang menangani kegiatan usaha syariah. 
Jurnal Ekonomi Syariah Darussalam

Vol I No I Agustus 2020, ISSN: 2745-8407

Konsep operasi pegadaian syariah berfungsi untuk mengooperasikan Pegadaian Syariah selain dapat didirikan kantor-kantor Cabang Pegadaian Syariah atau Unit Layanan Gadai Syariah (ULGS) telah di sebutkan merupakan unit-unit bisnis mandiri dan tidak lama waktu itu terciptalah menyusul kemudian pendirian ULGS di Surakarta, Surabaya, Semarang dan Makasar pada tahun yang sama hingga sampai September 2003. Tetap ada ditahun yang sama pula, setelah itu didirikan empat Kantor Cabang Pegadaian di Aceh yang dikonvensikan menjadi Pegadaian Syariah.

PT. Pegadaian (Persero) Unit Pegadaian Syariah Simpang Lima Banyuwangi didirikan pada bulan April Tahun 2009. Saat ini Pegadaian Syariah Simpang Lima Banyuwangi di pimpin oleh Ibu Nurhidayah. PT. Pegadaian (Persero) Unit Pegadaian Syariah Simpang Lima Banyuwangi merupakan Unit yang mempunyai cabang di Jember dan memiliki pusat di Jakarta. Pegadaian Syariah satu-satunya yang ada di Banyuwangi yang memiliki cukup banyak nasabah. Kehadiran Pegadaian Syariah pertama di Banyuwangi ini merupkan kompetitor baru bagi pegadaian konvensional yang telah memiliki banyak cabang di Banyuwangi (Wawancara, Nurhidayah Tanggal 12-07-2019 jam 09.30).

\section{Gambaran Umum Data Lapangan}

PT. Pegadaian (Persero) Unit Pegadaian Syariah Simpang Lima di Kabupaten Banyuwangi didirikan pada Bulan April Tahun 2009 yang di pimpin oleh Ibu Nurhidayah sampai sekarang PT. Pegadaian (Persero) Unit Pegadaian Syariah Simpang Lima di Kabupaten Banyuwangi merupakan Unit satu-satunya di Kabupaten Banyuwangi dan mempunyai cabang di Jember dan memiliki pusat di Jakarta. Pegadaian Syariah juaga memiliki cukup banyak nasabah. Kehadiran pegadaian syariah pertama di Kabupaten Banyuwangi ini merupakan kompetitor baru bagi pegadaian konvensional yang telah memiliki banyak cabang di Kabupaten Banyuwangi (Wawancara, Nurhidayah Tanggal 12-07-2019 jam 09.30).

\section{Temuan Penelitian}

Dalam upaya untuk meningkatkan jumlah nasabah di tinjau dari perspektif Islam yang diterapkan PT. Pegadaian (Persero) Unit Pegadaian Syariah Simpang Lima di Kabupaten Banyuwangi, maka dari hasil pengumpulan data lapangan 
Jurnal Ekonomi Syariah Darussalam

Vol I No I Agustus 2020, ISSN: 2745-8407

ditemukan beberapa permasalahan dan pembahasan dalam penelitian tersebut akan dijelaskan seperti uraian dibawah ini.

Penerapan strategi pemasaran strategi pemasaran produk-produk Gadai Syariah yang dilakukan oleh PT. Pegadaian (Persero) Unit Pegadaian Syariah Simpang Lima di Kabupaten Banyuwangi.

Informan memiliki penerapan yang berbeda-beda tentang strategi pelayanan Islami yang diterapkan di Pegadaian Syariah Simpang Lima di Kabupaten Banyuwangi, namun secara umum pandangan para informan yang merupakan pimpinan pengelolaan dan karyawan unit Pegadaian Syariah Simpang Lima di Kabupaten Banyuwangi terhadap strategi pelayanan Islami mengarah kepada pelayanan secara syariat Islam. Pernyataan para infoman terkait penerapan strategi pemasaran syariah adalah sebagai berikut:

"Dalam hal strategi produk dilakukan dengan cara pengembangan produk Ar-rahn menjadi Arrum (Ar-rahn untuk usaha mikro kecil) dan mengoptimalkan taksiran. Dalam hal strategi harga yaitu dengan memotong tarif ijarah dari Rp 85 menjadi Rp. 80 setian Rp 10.000 nilai taksiran. Dalam hal distribusi yaitu dengan cara membuka UPC (Unit Pelyanan Cabang) kecil agar mudah dijangkau oleh nasabah dalam hal strategi promosi yaitu dengan cara periklanan, berupa brosur, spanduk, souvenir, dan personal selling melalui sosialisasi. Pemasaran dilakukan di bawah naungan devisi syariah dan OPP (Operasi Pemasaran Pusat) Kanwil (Kantor Wilayah)" (Ibu Nur Hidayah selaku Pimpinan Pegadaian Syariah 17 Juni 2019 jam $12.00 \mathrm{WIB})$.

"Iya, nasabah mengalami kenaikan setiap tahunya, dan Alhamdulillah tidak pernah menurun, dulu waktu pertama kali perusahaan berdiri belum mempunyai marketing tetapi tetap melakukan promosi yang dilaksanakan oleh para semua staf dan khususnya staf office boy setiap kali pas lagi off. Perusahaan ini berdiri pada tahun 2009 sampai dengan 2014 baru mempunyai marketing mas Ishom itu, Alhamdulillah semenjak ada marketing nasabahnya mengalami banyak peningkatan dari yang sebelumnya (sebelum punya marketing). Iya data nasabahnya dulu nya masih di download sudah dari tadi tapi kok gak bisa-bisa nya apa besok saja? Mulai dari tahun 2016 perusahaan mempunyai nasabah 6998, dan 2017 ke 2018 mengalami kenaikan lagi dari 8063 nasabah menjadi 10.078 nasabah" (Ibu Nur Hidayah selaku Pimpinan Pegadaian Syariah 17 Juni 2019 jam $12.30 \mathrm{WIB})$.

"Dari luar memang banyak sekali pesain baik yang formal maupun yang non formal. Tetapi perusahaan dalam menghadapi tidak mengebu-nggebu. Perusahaan hanya saja mengedepankan layanan yang baik kepada setiap nasabah. Bayangkan saja kalau kita jadi konsumen beli di pasar yang harganya murah tetapi pelayanannya tidak enak dan beli di supermarket yang pelayanan nya ramah, senyum sapa, pasti kita akan memilih di pelayananya yang enak walaupun harga 
Jurnal Ekonomi Syariah Darussalam

Vol I No I Agustus 2020, ISSN: 2745-8407

nya mahal” Ibu Nur Hidayah selaku Pimpinan Pegadaian Syariah 17 Juni 2019 jam 12.30 WIB).

Dari pemaparan yang disampaikan para informan diatas adalah promosi yang di terapkan di pegadaian syariah dengan beberapa macam promosi, diantaranya:

1. Promosi reveral

2. Promosi sebar brosur

3. Promosi telle marketing

Selain itu harus sesuai SOP Pegadaian Syariah. Ketika membukakan pintu maka harus dengan senyum, sapa dan salam. Kemudian ketika memasarkan sebuah produk dengan cara face to face. Memaksimalkan SOP disini yakni pelayanan secara Syar'i. Menurut informan karyawan yang kedua menyatakan bahwa penerapan strategi pelayanan Islami dilihat dengan keadaan dilapangan atau dikantor, memberikan pelayanan Islami dari karyawan perempuan dengan memakai hijab dan karyawan laki-laki harus berpakaian sopan, dalam memberikan pelayanan Islami nasabah akan mendapat pelayanan seperti sapaan, dan karyawan melayani dengan tanggap.

Strategi pemasaran produk-produk Gadai Syariah Simpang Lima Banyuwangi ditinjau dari perspektif Islam yaitu: Apakah dalam menjalankna promosi di PT. Pegadaian (persero) Syariah Simpang Lima Banyuwangi semua yang disampaikan sesuai dengan apa yang ada di perusahaan. Dalam hal ini wawancara Nurhidayah, dan Nur Khishom menyatakan sebagai berikut:

"Dalam menjalankan promosi telah sesuai dengan ketentuan yang telah di tetapkan oleh perusahaan. Yaitu dilakukan dengan lemah lembut, menyapa calon nasabah dengan ramah dan bersifat tidak memaksa, dan juga menyampaikan harga-harga produk sesuai dengan apa yang ada di perusahaan pada saat itu yang di butuhkan oleh calon nasabah" (Ibu Nur HIdayah selaku Pimpinan Pegadaian Syariah 17 Juni 2019 jam 13.00 WIB).

Apakah dalam menjalankan promosi dan dalam melayani nasabah sesuai dengan sikap sidiq, amanah, fathanah, dan tabliq? Iya dalam melayani nasabah pokok kita melakukan dengan sebaik mungkin misalkan dalam sifat:

"Sidiq, dalam melayani nasabah telah mengikuti prosedur pelayanan yang telah di tetapkan oleh perusahaan yaitu menggunakan $3 S$ salam, senyum, sapa, dan mendahulukan nasabah yang datang lebih awal. Amanah, menjaga barang nasabah yang dijadikan sebagai barang jaminan sesuai dengan shof perusahaan, Fathanah, ketika sedang menghadapi nasabah yang bermasalah maka memberi 
Jurnal Ekonomi Syariah Darussalam

Vol I No I Agustus 2020, ISSN: 2745-8407

solusi yang solutif, mendengarkan semua keluhanya dan mencoba mencarikan solusi nasabah.

Dari pemaparan yang disampaikan informan diatas pelayanan prima yang di gunakan oleh Pegadaian Syariah Simpang Lima di Kabupaten Banyuwangi adalah mencermati keinginan nasabah dan simpatik serta empati terhadap nasabah. Informan lain juga menyatakan bahwa pelayanan prima yang dilakukan adalah pelayanan secara khusus terhadap nasabah dan memenuhi kebutuhan nasabah dengan bertujuan menyenangkan nasabah serta memberi kepuasan terhadap nasabah.

Bagaiamanakah cara perusahaan menghadapi banyak pesaing? Solusi apa yang di telah dilakukan oleh perusahaan?

"Solusinya ya menambah pelanggan ya itu tadi pelayanan cepat dan tanggap, dengar keluhan pelanggan, dan mencari solusi yang tepat jadi kalau nasabah pinginnya gitu, misalkan wah, barang saya kelelang dan nasabah marah-marah gak dihubungi padahal kita udah kasih tau, ini udah ditelepon atau di WA terus gaka ada tanggapan dan sudah kita persurat tapi kita ada solusi karna barang sudah terjual sesuai prosedur itu kita carikan solusi lagi biar nasabah gak marah, namanya nasabah kalau salah itu gak bisa disalahkan jadi itu atau kita mesti gini untuk menjaga nama baik nasabah, misalnya udah sampai tanggal batas, dihubungi gak bisa maka solusinya ya kita pending dulu, jadi kita sitem lelang sesuai prosedur dan kita gadaikan lagi. Kemudian menjada kesabaran dan kesopanan, akui kesalahan jadi kalau kita yang salah kepada nasabah maka akui saja kesalahannya dan minta maaf kepada nasabah, kemudian tepati janji jadi ketika kita udah janjian kepada nasabah ya kita tepati janjinya dan perusahaan juga menggunakan strategi pelayanan Islami yang di lakukan di Pegadaian Syariah ada beberapa macam yaitu: 1) Pelayanan dengan lisan dengan pelayanan tiga S, yaitu Senyum, Sapa, Salam. 2) Pelayanan tulisan degan tujuan untuk mempermudah nasabah, agar tau mana kasir dan mana penaksirnya, 3) Pelayan perbuatan, maksud dari pelayanan ini yaitu kita berbuat sopan terhadap nasabah 4) Pelayanan terhadap keluhan nasabah, entah itu complain atau dia mengeluh pribadinya itu kita dengarkan dengan sabar dan tenang kalau nasabah marah kita harus menahannya, nah itu salah satu cara meredakan amarah. Jadi kita tidak selalu fokus dengan produk orang lain tetapi kita juga memberikan fasilitas yang unggul bagi nasabah. Misalkan kita beli di toko yang harga nya murah tetapi pelayanannya tidak ramah, tidak sopan dan mbentak- mbentang dengan beli di toko swalayan besar yang mahal harganya pasti kebanyakan konsumen memilih toko yang baik pelayananya" (Wawancara pada Mas Nur Khishom Reza hari minggu 15 Juni 2019 jam 21.00).

Dari pemaparan diatas menjelaskan beberapa menghadapi banyak pesaing adalah tetap menjaga pelayanan dan selalu berkata sopan, lemah lembut dalam berbicara. Dan tidak berkata kasar disaat nasabah bertanya, tidak sopan saat 
Jurnal Ekonomi Syariah Darussalam

Vol I No I Agustus 2020, ISSN: 2745-8407

melayani nasabah, melakukan kekerasan terhadap nasabah, dan harus tahan emosi serta berpakaian dengan rapi. Menurut informan karyawan Pegadaian Syariah juga mengatakan bahwa larangan-larangan tersebut adalah tidak boleh memakai seragam dengan tidak sesuai jadwal, tidak memerdulikan ketika ada nasabah datang, tidak sopan terhadap nasabah, berbicara dengan keras. Menurut informan yang lain larangan-larangan strategi pelayanan Islami yang diterapkan itu sudah ada, tetapi hal perlu diketahui yakni para karyawan dalam memberikan sebuah informasi kepada nasabah terutama nasabah baru terkadang tidak menjelaskan secara mendetail itu yang terjadi di lapangan.

\section{Pembahasan}

Menurut banyak ulama yang mengatakan atau menyebutkan bahwa telah ada ijma' tentang haramnya melakukan jenis promosi yang mengandung dan mempunyai unsur penipuan yang di dalamnya terdapat pengelabuhan atau tidak kesesuaian, penyamaran maupun menyebutkan sifat yang tidak sesuai dengan kondisi produk yang dijual dan di dalam mempromosikan barang tidak boleh menggunakan kata gharar (sumpah) seperti telah disebutkan dalam Al-Qur'an terjemah Bi Rosm Utsmani Qs. Al- Imran Ayat 77:

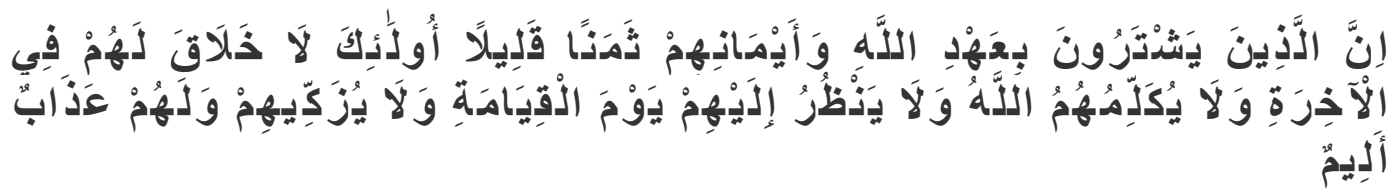

Artinya: "Sesungguhnya orang-orang yang menukar janji (nya dengan) Allah dan sumpah-sumpah mereka dengan harga yang sedikit, mereka itu tidak mendapat bahagian (pahala) di akhirat, dan Allah tidak akan berkatakata dengan mereka dan tidak akan melihat kepada mereka pada hari kiamat dan tidak (pula) akan mensucikan mereka. Bagi mereka azab yang pedih".

Ayat ini diturunkan berkaitan dengan orang yang menyamarkan kondisi real dari barang dagangannya di pasar, sedangkan dia bersumpah demi Allah bahwasanya barang tersebut adalah barang kualitas terbaik, dengan tujuan ada orang Islam yang tertipu dengan yang dilakukan disebabkan sumpah palsu dari penjual tersebut. Hal ini menunjukkan diharamkannya seseorang yang melakukan sumpah dusta agar dagangannya laris dan dibeli orang lain. Seperti hasil wawancara Hidayah (2019) dapat diketahui bahwa yang dilakukan oleh Pegadaian Syariah Simpang Lima di Kabupaten Banyuwangi dalam menerapkan strategi promosi pemasaran syariah dengan menggunakan beberapa macam bentuk promosi yang 
Jurnal Ekonomi Syariah Darussalam

Vol I No I Agustus 2020, ISSN: 2745-8407

secara syariah dan sesuai dengan Islam. Selain itu, Pegadaian Syariah Simpang Lima di Kabupaten Banyuwangi tersebut selalu mementingkan etika pelayanan dalam berperilaku, dengan memperhatikan apa yang dibutuhkan oleh nasabah (Kasali, 2019:8).

Hasil wawancara dengan para informan yaitu Ibu Nurhidayah (2019) selaku pimpinan pengelolaan dan Bapak Nur Khishom Reza (2019) selaku marketing Unit Pegadaian Syariah Simpang Lima di Kabupaten Banyuwangi yang menyatakan bahwa strategi pemasaran syariah tersebut menerapkan berbagai etika seperti etika kesopanan, bekerja dengan ikhlas, dan selalu mementingkan etika berperilaku dalam melayani. Hal ini serupa juga yang diungkapkan para nasabah unit Pegadaian Syariah Simpang Lima di Kabupaten Banyuwangi bahwa pelayanan Islami yang dilakukan pegadaian tersebut sangat baik, selalu menyampaikan informasi, menguntungkan dan memudahkan nasabah, dan para karyawannya pun juga cepat tanggap, bersikap sopan, ramah, rendah hati dan penuh tanggung jawab. Salah satu etika pemasaran syariah yaitu etika untuk selalu menyampaikan yang benar dan etika untuk selalu mengerjakan dengan ikhlas. Penerapan strategi peamasaran syariah di Pegadaian Syariah sebenarnya sudah ada atau sudah diterapkan di lembaga, cuma terdapat perbedaannya yaitu dalam memberikan penjelasan mengenai transaksi gadai kepada nasabah baru terkadang tidak secara mendetail. Hasil analisis yang telah dipilih guna menjadi alternatif strategi pemasaran syariah yang ada pada PT. (Persero) Unit Pegadaian Syariah Simpang Lima di Kabupaten Banyuwangi adalah menggunakan analisis SWOT merupakan salah satu pemulihan dan pengelolaan SWOT yang ada di Unit Pegadaian Syariah Simpang Lima di Kabupaten Banyuwangi. Menurut Ibu Nurhidayah waktu wawancara selaku pimpinan pengelolaan Unit Pegadaian Syariah Simpang Lima di Kabupaten Banyuwangi, mengemukakan masalah analisis SWOT di Pegadaian Syariah Simpang Lima di Kabupaten Banyuwangi sebagai berikut:

Pertama, Kekuatan (Strength) yaitu meliputi: Kualitas produk yang ditawarkan baik, adanya pembagian souvenir, promosi dilakukan lewat media reveral telle marketing, dan social media, brosur yang digunakan di desain kecil, lokasi Pegadaian Syariah yang strategis. 
Jurnal Ekonomi Syariah Darussalam

Vol I No I Agustus 2020, ISSN: 2745-8407

Kedua, Kelemahan (Weakness) yaitu meliputi: Produk masih kalah saing dengan pihak bank lain, strategi promosi yang kurang, lokasi bank lain lebih strategis.

Ketiga, Peluang (Opportunity) yaitu meliputi: Variasi produk yang semakin banyak dan menarik, luasnya pangsa pasar, perkembangan teknologi, hubungan yang baik dengan nasabah, kemajuan teknologi yang semakin canggih.

Keempat Ancaman (Threath) yaitu meliputi: Gencarnya promosi iklan dari kompotitor, konsumen yang beralih ke perusahaan lain dan pemahaman nasabah yang kurang mengenai konsep syariah.

\section{E. KESIMPULAN}

Berdasarkan hasil penelitian dan pembahasan, maka dapat ditarik kesimpulan bahwa strategi pemasaran syariah pelayanan diterapkan di Pegadaian Syariah yaitu dengan beberapa macam pelayanan diantaranya pemasaran secara syariat Islam, promosi syariah, pelayanan dalam pandangan Islam, serta kendala-kendala yang di alami dihadapi dengan etika pelayanan Islami yang akan menunjukkan peningkatan jumlah nasabah setiap tahunnya. Hasil analisis yang telah dipilih guna menjadi alternatif strategi pemasaran syariah yang ada pada PT. (Persero) Unit Pegadaian Syariah Simpang Lima di Kabupaten Banyuwangi adalah menggunakan analisis SWOT, maka dapat ditarik kesimpulan bahwa:

1. Strategi SO (Kekuatan dan Peluang)

a. Promosi yang di kuaatkan dengan dukungan masyarakat;

b. Meningkatkan promosi dengan membuat iklan di internet;

c. Memanfaatkan pemasaran dan pelayanan secara Syar'i guna untuk menarik simpatik dan empati nasabah aktif Pegadaian Syariah.

2. Strategi ST (Peluang dan Ancaman)

a. Mengembangkan daya saing dengan memberikan pelayanan Islami yang terbaik;

b. Mempunyai inovasi sehingga memiliki karakter yang berbeda.

3. Strategi WO (Kelemahan dan Peluang)

a. Perusahaan menyediakan produk yang diinginkan masyarakat sesuai dengan kebutuhan masing-masing; 
Jurnal Ekonomi Syariah Darussalam

Vol I No I Agustus 2020, ISSN: 2745-8407

b. Meningkatkan sosialisasi yang lebih gencar di semua media untuk mendapatkan loyalitas nasabah.

4. Strategi WT (Kelemahan dan Ancaman)

a. Perusahaan melayani semua kalangan masyarakat dengan ramah dan tidak membedakan antara kaum muslim dan non muslim;

b. Meningkatkan daya saing produk dengan mempertahankan ciri khas produk.

\section{DAFTAR PUSTAKA}

Ahmadi, Rulam. 2014. Metodologi Penelitian Kualitatif. Yogyakarta: Ar-Ruzz Media.

Al Arif, M Nur Rianto. 2017. Lembaga Keuangan Syariah (Suatu Kajian Teoritis Praktis). Bandung: CV Pustaka Setia.

Arifin, Johan. 2014. Etika Bisnis Islami. Semarang: Walisongo Press.

Arista, Linda Arita. 2014. Analisis Strategi Pelayanan dalam Menghadapi Persaingan Bisnis di BMT Sahara Tulungagung. Penelitian. Institut Agama Islam Negeri (IAIN) Tulungagung.

Assauri, Sofjan. 2004. Manajemen Pemasaran Dasar, Konsep, dan Strategi. Jakarta: PT Raja Grafindo Persada.

Ekaningsih, Lely Ana Ferawati. 2016. Lembaga Keuangan Syariah Bank dan Non Bank. Surabaya: Kopertais.

Habiburrahim. 2012. Mengenal Pegadaian Syariah (Prinsip-prinsip Dasar dalam Menjalankan Usaha Pegadaian Syariah). Jakarta: Kuwais.

Indonesia, Ikatan Bankir. 2014. Memahami Bisnis Bank Islam. Jakarta: PT Grafindo Pustaka Utama.

Kasmir. 2005. Pemasaran Bank. Jakarta: Kencana.

Kotler, Philip. 2005. Manajemen Pemasaran di Indonesia: Analisis, Pemasaran, Implementasi dan Pengendalian, Terjemah: A. B. Susanto, Edisi Pertama. Jakarta: Salemba Empat.

Rangkuti, Freddy. 2009. Analisis SWOT Teknik Membedah Kasus Bisnis. Jakarta: PT Gramedia Pustaka Utama.

Sabariah, Etika. 2016. Manajemen Strategis. Yogyakarta: Pustaka Belajar.

Sugiyono. 2017. Metodologi Penelitian Kuantitatif, kualitatif dan R\&D. Bandung: Alfabeta.

Tjiptono, Fandy. 2002. Strategi Pemasaran. Yogyakarta: Andi Offset.

Usman. 2003. Managemen Strategik. Yogyakarta: Amara Blok. 